\title{
The impact of hospital language on the rate of in-hospital harm. A retrospective cohort study of home care recipients in Ontario, Canada
}

Michael Reaume ${ }^{1,2^{*}}$, Ricardo Batista ${ }^{3,4}$, Robert Talarico ${ }^{4}$, Emily Rhodes $^{3}$, Eva Guerin², Sarah Carson ${ }^{1,2}$, Denis Prud'homme 2,5 and Peter Tanuseputro ${ }^{1,3,4,6}$

\begin{abstract}
Background: Patients who live in minority language situations are generally more likely to experience poor health outcomes, including harmful events. The delivery of healthcare services in a language-concordant environment has been shown to mitigate the risk of poor health outcomes related to chronic disease management in primary care. However, data assessing the impact of language-concordance on the risk of in-hospital harm are lacking. We conducted a population-based study to determine whether admission to a language-discordant hospital is a risk factor for in-hospital harm.

Methods: We used linked administrative health records to establish a retrospective cohort of home care recipients (from 2007 to 2015) who were admitted to a hospital in Eastern or North-Eastern Ontario, Canada. Patient language (obtained from home care assessments) was coded as English (Anglophone group), French (Francophone group), or other (Allophone group); hospital language (English or bilingual) was obtained using language designation status according to the French Language Services Act. We identified in-hospital harmful events using the Hospital Harm Indicator developed by the Canadian Institute for Health Information.

Results: The proportion of hospitalizations with at least 1 harmful event was greater for Allophones (7.63\%) than for Anglophones (6.29\%, $p<0.001)$ and Francophones (6.15\%, $p<0.001)$. Overall, Allophones admitted to hospitals required by law to provide services in both French and English (bilingual hospitals) had the highest rate of harm (9.16\%), while Francophones admitted to these same hospitals had the lowest rate of harm (5.93\%). In the unadjusted analysis, Francophones were less likely to experience harm in bilingual hospitals than in hospitals that were not required by law to provide services in French (English-speaking hospitals) ( $R R=0.88, p=0.048$ ); the opposite was true for Anglophones and Allophones, who were more likely to experience harm in bilingual hospitals ( $R R=1.17, p<0.001$ and $R R=1.41, p<0.001$, respectively). The risk of harm was not significant in the adjusted analysis.

(Continued on next page)
\end{abstract}

\footnotetext{
* Correspondence: michael.reaume@uottawa.ca

${ }^{1}$ Faculty of Medicine, University of Ottawa, 451 Smyth Rd, Ottawa, ON K1H

8L1, Canada

${ }^{2}$ Institut du Savoir Montfort, Ottawa, Canada

Full list of author information is available at the end of the article
}

\section{$\triangle B M C$}

(c) The Author(s). 2020 Open Access This article is licensed under a Creative Commons Attribution 4.0 International License, which permits use, sharing, adaptation, distribution and reproduction in any medium or format, as long as you give appropriate credit to the original author(s) and the source, provide a link to the Creative Commons licence, and indicate if changes were made. The images or other third party material in this article are included in the article's Creative Commons licence, unless indicated otherwise in a credit line to the material. If material is not included in the article's Creative Commons licence and your intended use is not permitted by statutory regulation or exceeds the permitted use, you will need to obtain permission directly from the copyright holder. To view a copy of this licence, visit http://creativecommons.org/licenses/by/4.0/ The Creative Commons Public Domain Dedication waiver (http://creativecommons.org/publicdomain/zero/1.0/) applies to the data made available in this article, unless otherwise stated in a credit line to the data. 
(Continued from previous page)

Conclusions: Home care recipients residing in Eastern and North-Eastern Ontario were more likely to experience harm in language-discordant hospitals, but the risk of harm did not persist after adjusting for confounding variables.

Keywords: Harmful events, Language barriers, Language concordance, Language discordance, Linguistic minorities, Patient safety

\section{Background}

Linguistic diversity in North America is increasing at an unprecedented rate. In the United States, approximately 67 million people (22\% of the population) primarily speak a language other than English, of which 39\% speak English less than "very well" [1]. The situation is similar in Canada, where almost 9 million people $(25 \%$ of the population) live in a province that does not recognize their mother tongue as an official language [2]. Despite government-led initiatives to improve the delivery of healthcare services to minority linguistic groups, health disparities related to access, quality, and safety of care persist across linguistic groups [3-6].

There is a growing body of evidence that language barriers may contribute to the health disparities observed across linguistic groups. The majority of previous studies have considered the relationship between a patient's linguistic group and specific health-related outcomes. For instance, studies have shown that linguistic groups who live in minority language situations face barriers when accessing healthcare services [7, 8], have longer emergency department visits and hospitals stays [9, 10], receive lower quality discharge documentation and discharge instructions $[11,12]$, have higher rates of hospital admissions and re-admissions [13, 14], and experience more harmful events in hospitals [15-18]. However, due to limitations regarding inaccurate measurement of patients' primary language and inadequate adjustment of confounding variables, it is not known whether the differences in these studies are due to language barriers, or to systematic differences in patient characteristics (e.g., socioeconomic status) and/or health status across linguistic groups.

Few studies have directly assessed the impact of patient-provider language discordance, which occurs when the patient and their provider lack proficiency in a shared language. Studies conducted in the United States show that Spanish-speaking patients are more likely to attend scheduled office appointments [19], ask questions during appointments $[20,21]$, report better health outcomes [22], receive more health education [23-25], and have better recall of health information [20, 23] when cared for by Spanish-speaking physicians. Languageconcordant care has been shown to result in objective benefits for specific health outcomes related to chronic disease management, such as better control of diastolic blood pressure [26], glycemia [26-28], and low-densitylipoprotein levels [26], among patients with type 2 diabetes. Another study found an increase in 1-year allcause mortality among Canadian immigrants treated for tuberculosis in the presence of patient-provider language discordance, when compared to immigrants treated by physicians who were proficient in their language [29].

To our knowledge, no population-level study has considered the relationship between patient-provider language discordance and the risk of harmful events in acute care settings. In Canada, one out of 18 patients admitted to hospital experiences a harmful event, which is generally defined as an unintended outcome with negative consequences that could potentially be prevented with evidence-based practices [30]. The purpose of this study was to compare the incidence of in-hospital harm across linguistic groups in Ontario, Canada, and determine whether admission to a language-discordant hospital is a risk factor for in-hospital harm, before and after adjusting for potentially confounding variables.

\section{Methods}

\section{Study design and population}

We conducted a population-based retrospective cohort study in Ontario, Canada, using administrative databases. We included Ontario residents who received publicly funded home care services from April 1, 2007 to March 31, 2015 and who were hospitalized within 2 years of their first home care assessment, conducted using the Resident Assessment Instrument for Home Care (RAI-HC) [31]. Respondents of the RAI-HC are typically frail (e.g., have limitations in activities in daily living and limited life expectancy), and are assessed for language status [32, 33]. We excluded residents who were older than 105 years of age at the time of the study or not eligible for Ontario's universal health insurance plan (i.e., the Ontario Health Insurance Plan (OHIP)) during the study period. In 2007, the planning and distribution of public healthcare services in Ontario was divided into 14 geographically defined local health integration networks (LHINs) [34]. We included home care recipients who resided in the Champlain and North-East LHINs; this allowed us to consider regions where Francophones (according to mother tongue) represent an important proportion of the population $(18.5 \%$ in the Champlain LHIN and $22.3 \%$ in the North-East 
LHIN according to the 2016 Canadian Census). By comparison, the proportion of Francophones in all other LHINs is less than $3.1 \%$, and Allophones (i.e., residents whose mother tongue is not English or French) represent 16.8 and $6.2 \%$ of the population in the Champlain and North-East LHINs, respectively [2].

The RAI-HC database, which captures the baseline characteristics of Ontario residents receiving publicly funded home care services for at least 60 consecutive days or while waiting for admission into long-term care [35], allowed us to study a cohort of frail, older residents with an increased risk of hospitalization and harm [32, 33]. Residents who completed more than one home care assessment were indexed at the time of their first assessment and followed for 2 years. Thus, all home care recipients appeared once in the baseline cohort and were censored at 2 years or at death (whichever occurred first). Patients with multiple hospitalizations were considered as separate entries when calculating the incidence of harm (i.e., one entry per hospitalization) in order to capture the total incidence of harm during the follow-up period.

\section{Data sources}

Baseline characteristics were obtained from the following databases: RAI-HC database; Registered Persons Database, which captures resident-level information, such as age, sex, and postal code; and Facilities Database, which captures hospital-level information for all institutions funded by the Ministry of Health and Long-Term Care. Patient and hospital postal codes were linked to the 2011 Statistics Canada Census to obtain income quintile and urban/rural status at the level of the patients and hospitals, respectively [36]. Chronic conditions were identified using algorithms validated by ICES (formerly known as the Institute for Clinical Evaluative Sciences) and applied in previous studies (see Additional file 1) [33, 37-39]. Outcomes were obtained from the Discharge Abstract Database (DAD), which captures information on all admissions to acute care hospitals.

\section{Exposure}

Patient language was obtained from the RAI-HC home care assessment, where interviewers record the language that the home care recipient primarily speaks and/or understands. Interviewers also consult clinical records, family members, and referral sources to identify home care recipients who need an interpreter [31]. We considered three main linguistic groups: Anglophone (i.e., primary language English), Francophone (i.e., primary language French), and Allophone (i.e., primary language is a language other than English or French).

Hospital language was defined using language designation status according to the French Language Services
Act [40], which is a provincial law that requires government agencies to provide all of their services in both French and English. Currently, 12 acute care hospitals in Ontario (4 in Champlain LHIN and 8 in North-East LHIN) are required by law to provide all of their services in both French and English. The remaining 147 acute care hospitals are only required by law to provide all of their services in English. We defined these hospitals as "bilingual hospitals" and "English-speaking hospitals," respectively.

\section{Outcomes}

In-hospital harmful events were identified using the Hospital Harm Indicator developed by the Canadian Institute for Health Information [30]. The Hospital Harm Indicator uses International Statistical Classification of Diseases and Related Health Problems, 10th Revision, Canada codes recorded in the DAD to identify harmful events occurring during a hospitalization (Additional file 2 ). The indicator combines information from diagnosis clusters, diagnosis codes, diagnosis types, and intervention codes to classify each in-hospital harmful event into one of the following four categories: i) harm from general medical care, including medication administration (e.g., electrolyte and fluid imbalance, delirium); ii) infections (e.g., urinary tract infections, pneumonia); iii) patient accidents (e.g., falls); and, iv) harm from procedures (e.g., anemia or hemorrhage due to medical or surgical care, laceration/puncture) [30]. With the exception of patient accidents, every category of harmful events can be divided into additional subcategories, for a total of 31 subcategories, which are provided in Additional file 2 [30]. We defined a "harmful hospitalization" as a hospitalization with at least one harmful event. Some patients experienced multiple harmful events during a single hospitalization. In these cases, we assigned each harmful event to its respective category, and we treated the hospitalization as a single harmful hospitalization. Thus, a harmful hospitalization could include harm from health care-associated conditions, infections, patient accidents, and/or procedures.

\section{Statistical analysis}

We performed descriptive analyses to compare patient and hospital characteristics across linguistic groups and hospital language, respectively. Means (+/- standard deviation) were reported for continuous variables, and proportions were reported for categorical variables. Baseline characteristics were compared using analysis of variance (ANOVA) for continuous variables and chi-squared tests for categorical variables.

We compared outcomes across hospitals (i.e., Englishspeaking and bilingual) after stratifying by patient language. We considered three linguistic groups (i.e., 
Anglophone, Francophone, Allophone) in three separate models to determine the impact of hospital language on the rate of harm within each linguistic group. Thus, each model compared outcomes for patients admitted to bilingual hospitals to those admitted to English-speaking hospitals for a given linguistic group. Patients in English-speaking hospitals were the reference group in all three models.

We obtained both unadjusted and adjusted estimates of the relative risk. Unadjusted estimates were calculated using the method described by Katz et al. [41], while adjusted estimates were obtained using a modified Poisson regression with generalized estimating equations to account for hospital-level clustering [42-44]. Adjusted regression analyses included potential confounders related to both patient characteristics (age at admission, sex, marital status, education, neighbourhood-level income quintile, urban/rural residence, Charlson Comorbidity Index [45], Activities of Daily Living (ADL) scale [46], Cognitive Performance Scale [47]) and hospital characteristics (academic institution (yes/no), emergency department at hospital (yes/no), urban/rural status of hospital, number of ICU beds, number of medical beds, number of obstetric beds, number of pediatric beds, and number of surgical beds). We excluded observations with incomplete or missing data for primary language $(n=3)$. Statistical tests were two-tailed, and the significance threshold was set at 0.05 .

\section{Ethics approval}

ICES (formerly known as the Institute for Clinical Evaluative Sciences) is a prescribed entity under section 45 of Ontario's Personal Health Information Protection Act. Section 45 authorizes ICES to collect personal health information, without consent, for the purpose of analysis or compiling statistical information with respect to the management of, evaluation or monitoring of, allocation of resources to or planning for all or part of the health system. This project was conducted under section 45 and approved by the ICES Privacy and Compliance Office.

\section{Results}

\section{Baseline characteristics}

We included 50,267 long-stay home care recipients residing in the Champlain and North-East LHINs who met eligibility criteria. The majority of home care recipients were Anglophone (77.5\%), while Francophones and Allophones represented 16.0 and $6.4 \%$ of the cohort, respectively. The baseline characteristics of Anglophones, Francophones, and Allophones are presented in Table 1. Compared to Anglophones and Francophones, Allophones tended to be older and were more likely to be married or in a common-law relationship. There was a greater proportion of females among Francophones than among Anglophones and Allophones. Both Francophones and Allophones were less likely to have completed high school than Anglophones. The proportion of residents living in lower-income neighbourhoods and in rural areas was greater for Francophones than both Anglophones and Allophones. Anglophones and Allophones had a similar distribution of neighbourhood income levels, while a greater proportion of Allophones lived in urban areas.

The functional status and health characteristics of the cohort are presented in Table 2. Francophones tended to have more chronic conditions when compared to Anglophones and Allophones $(p=0.010)$. However, there was no significant difference in measures of comorbidity (Charlson Comorbidity Index; $p=0.319$ ) or health decline (Changes in Health, End-Stage Disease, Signs and Symptoms (CHESS) score; $p=0.213$ ) across linguistic groups. Anglophones and Francophones were similar in terms of functional status and cognitive performance, while Allophones were less likely to perform their activities of daily living independently $(p<0.001)$ and more likely to have cognitive impairment $(p<0.001)$.

We identified 159 acute care hospitals in the Champlain and North-East LHINs. Of these hospitals, 12 (7.5\%) were required by law to provide all of their services in both French and English (bilingual hospitals), while 147 (92.5\%) were only required by law to provide all of their services in English (English-speaking hospitals). The characteristics of the hospitals are presented in Table 3. Bilingual hospitals were more likely to be academic institutions, to have an emergency department, and to be located in rural areas when compared to English-speaking hospitals. Bilingual hospitals also tended to have fewer beds overall, and within each unit (intensive care unit, medicine, obstetrics, pediatrics, surgery). However, none of these differences were significant at the 0.05 level.

\section{Harmful hospitalizations}

We identified 106,879 hospitalizations during the 2-year follow-up period. A total of 6788 (6.35\%) hospitalizations included at least one harmful event (Table 4). The proportion of harmful hospitalizations experienced by Allophones $(7.63 \%)$ was greater than that experienced by Anglophones (6.29\%; $p<0.001$ ) and Francophones (6.15\%; $p<0.001)$. The difference in the rate of harmful hospitalizations when comparing Anglophones and Francophones was not significant $(p=0.492)$. Francophone hospitals had a higher proportion of harmful hospitalizations than anglophone hospitals $(6.80 \%$ vs. $6.05 \%$; $p<0.001)$.

Overall, Allophones admitted to bilingual hospitals had the highest rate of harm $(9.16 \%)$, while 
Table 1 Baseline characteristics of hospitalized home care recipients, by patient linguistic group

\begin{tabular}{|c|c|c|c|c|}
\hline Baseline Characteristic & Anglophone $(N=38,975)$ & Francophone $(N=8053)$ & Allophone $(N=3239)$ & $\boldsymbol{P}$ value $^{*}$ \\
\hline Age at admission (years) - mean +/- s.d. & $76.6 \pm 13.1$ & $77.1 \pm 11.9$ & $80.6 \pm 9.2$ & $<0.001$ \\
\hline \multicolumn{5}{|l|}{ Sex - no. (\%) } \\
\hline Female - no. (\%) & $22,458(57.6 \%)$ & $4765(59.2 \%)$ & $1842(56.9 \%)$ & \multirow[t]{2}{*}{0.002} \\
\hline Male - no. (\%) & $16,517(42.4 \%)$ & $3288(40.8 \%)$ & $1397(43.1 \%)$ & \\
\hline \multicolumn{5}{|l|}{ Marital Status - no. (\%) } \\
\hline Not Married & $22,812(58.5 \%)$ & $4801(59.6 \%)$ & $1770(54.6 \%)$ & \multirow[t]{3}{*}{$<0.001$} \\
\hline Married or Common-Law & $15,503(39.8 \%)$ & 3133 (38.9\%) & $1446(44.6 \%)$ & \\
\hline Other & $660(1.7 \%)$ & $119(1.5 \%)$ & $23(0.7 \%)$ & \\
\hline \multicolumn{5}{|l|}{ Education - no. (\%) } \\
\hline Less than High School & $13,179(33.8 \%)$ & $4268(53.0 \%)$ & $1419(43.8 \%)$ & \multirow[t]{5}{*}{$<0.001$} \\
\hline High School & $6566(16.8 \%)$ & $833(10.3 \%)$ & $251(7.7 \%)$ & \\
\hline Some Post-Secondary & $5598(14.4 \%)$ & $697(8.7 \%)$ & $242(7.5 \%)$ & \\
\hline University Graduate & 3994 (10.2\%) & $425(5.3 \%)$ & $212(6.5 \%)$ & \\
\hline Missing & $9638(24.7 \%)$ & $1830(22.7 \%)$ & $1115(34.4 \%)$ & \\
\hline \multicolumn{5}{|l|}{ Income Quintile - no. (\%) } \\
\hline 1 (lowest) & $10,054(25.8 \%)$ & $2313(28.7 \%)$ & $883(27.3 \%)$ & \multirow[t]{6}{*}{$<0.001$} \\
\hline 2 & 7981 (20.5\%) & 1857 (23.1\%) & $672(20.7 \%)$ & \\
\hline 3 & 7446 (19.1\%) & 1615 (20.1\%) & $580(17.9 \%)$ & \\
\hline 4 & 7328 (18.8\%) & $1303(16.2 \%)$ & $576(17.8 \%)$ & \\
\hline 5 (highest) & $6051(15.5 \%)$ & $944(11.7 \%)$ & $513(15.8 \%)$ & \\
\hline Missing & $115(0.3 \%)$ & $21(0.3 \%)$ & $15(0.5 \%)$ & \\
\hline \multicolumn{5}{|l|}{ Urban/Rural Residence - no. (\%) } \\
\hline Urban & $28,089(72.1 \%)$ & $5420(67.3 \%)$ & 2867 (88.5\%) & \multirow[t]{3}{*}{$<0.001$} \\
\hline Rural & 10,868 (27.9\%) & $2630(32.7 \%)$ & $372(11.5 \%)$ & \\
\hline Missing & $18(0.0 \%)$ & $<5(0.0 \%)$ & N/A & \\
\hline
\end{tabular}

* Baseline characteristics were compared using analysis of variance (ANOVA) for continuous variables and chi-squared tests for categorical variables

Francophones admitted to these same hospitals had the lowest rate of harm (5.93\%), a 1.5 -fold relative difference. In English-speaking hospitals, the proportion of harmful hospitalizations was lowest for Anglophones (5.96\%) and highest for Francophones (6.75\%), while Allophones experienced an intermediate rate of harm (6.50\%).

\section{Risk of harm by patient and hospital language}

In the unadjusted analysis, Anglophones and Allophones were more likely to experience harm in bilingual hospitals than in English-speaking hospitals $(R R=1.17,95 \%$ CI $1.11-1.23$ and $R R=1.41,95 \%$ CI 1.19-1.67, respectively), while Francophones were less likely to experience harm in bilingual hospitals ( $R R=0.88$, 95\% CI 0.77 0.99) (Fig. 1). After adjusting for potential confounders, the relative risk of harm was not significant when comparing patients admitted to bilingual and Englishspeaking hospitals within each linguistic group (Table 5); Anglophones and Allophones were equally likely to experience harm in bilingual hospitals as they were in English-speaking hospitals $(\mathrm{RR}=0.89,95 \%$ CI $0.69-1.15$ and $\mathrm{RR}=0.98,95 \%$ CI $0.82-1.17$, respectively). For Francophones, the protective effect of being treated in a bilingual hospital did not persist in the adjusted analysis, but the point estimate was further from 1 than in the unadjusted analysis ( $\mathrm{RR}=0.88,95 \%$ CI $0.77-0.99$, adjusted $R R=0.75,95 \%$ CI 0.49-1.13) (Fig. 2).

\section{Discussion}

In this study, Allophones (7.63\%) were more likely to experience harm than Anglophones (6.29\%) and Francophones $(6.15 \%)$. The rate of harm was influenced by both patient language and hospital language. Allophones admitted to hospitals that were required by law to provide services in both French and English (i.e., bilingual hospitals) had the highest rate of harm $(9.16 \%)$, which represents a $54 \%$ increase in relative risk when compared to Anglophones admitted to hospitals that were not required to provide services in French (i.e., English-speaking hospitals). Francophones were $12 \%$ less likely to experience harm in bilingual hospitals than in English-speaking hospitals, while 
Table 2 Functional status \& health characteristics of hospitalized home care, by patient linguistic group

\begin{tabular}{|c|c|c|c|c|}
\hline Functional Status \& Health Characteristic & Anglophone $(N=38,975)$ & Francophone $(N=8053)$ & Allophone $(N=3239)$ & $\boldsymbol{P}$ value $^{*}$ \\
\hline Number of Chronic Conditions - mean +/- s.d. & $4.26 \pm 2.04$ & $4.33 \pm 2.09$ & $4.22 \pm 1.98$ & 0.010 \\
\hline Charlson Comorbidity Index - mean +/- s.d. & $2.07 \pm 2.15$ & $2.07 \pm 2.09$ & $2.13 \pm 2.08$ & 0.319 \\
\hline \multicolumn{5}{|l|}{ Activities of Daily Living Scale - no. (\%) } \\
\hline Independent & $24,356(62.5 \%)$ & $4986(61.9 \%)$ & $1637(50.5 \%)$ & \multirow[t]{7}{*}{$<0.001$} \\
\hline Supervision Required & $4142(10.6 \%)$ & $869(10.8 \%)$ & $415(12.8 \%)$ & \\
\hline Limited Impairment & $5546(14.2 \%)$ & $1184(14.7 \%)$ & $588(18.2 \%)$ & \\
\hline Extensive Assistance Required (1) & $2422(6.2 \%)$ & $529(6.6 \%)$ & $287(8.9 \%)$ & \\
\hline Extensive Assistance Required (2) & $1450(3.7 \%)$ & $283(3.5 \%)$ & $180(5.6 \%)$ & \\
\hline Dependent & $885(2.3 \%)$ & $173(2.1 \%)$ & $101(3.1 \%)$ & \\
\hline Total Dependence & $174(0.4 \%)$ & $29(0.4 \%)$ & $31(1.0 \%)$ & \\
\hline \multicolumn{5}{|l|}{ Cognitive Performance Scale - no. (\%) } \\
\hline Intact & $15,555(39.9 \%)$ & 3087 (38.3\%) & $984(30.4 \%)$ & \multirow[t]{7}{*}{$<0.001$} \\
\hline Borderline Intact & $6634(17.0 \%)$ & $1413(17.5 \%)$ & $558(17.2 \%)$ & \\
\hline Mild Impairment & $6830(17.5 \%)$ & $1513(18.8 \%)$ & $615(19.0 \%)$ & \\
\hline Moderate Impairment & $8218(21.1 \%)$ & $1626(20.2 \%)$ & $808(24.9 \%)$ & \\
\hline Moderate Severe Impairment & $577(1.5 \%)$ & 109 (1.4\%) & $94(2.9 \%)$ & \\
\hline Severe Impairment & $1029(2.6 \%)$ & $279(3.5 \%)$ & $149(4.6 \%)$ & \\
\hline Very Severe Impairment & $132(0.3 \%)$ & $26(0.3 \%)$ & $31(1.0 \%)$ & \\
\hline \multicolumn{5}{|l|}{ CHESS Score - no. (\%) } \\
\hline No Health Instability & 8095 (20.8\%) & $1589(19.7 \%)$ & $689(21.3 \%)$ & \multirow[t]{6}{*}{0.213} \\
\hline Minimal Health Instability & $11,570(29.7 \%)$ & $2370(29.4 \%)$ & $977(30.2 \%)$ & \\
\hline Low Health Instability & $10,969(28.1 \%)$ & $2302(28.6 \%)$ & $919(28.4 \%)$ & \\
\hline Moderate Health Instability & $6575(16.9 \%)$ & $1403(17.4 \%)$ & $496(15.3 \%)$ & \\
\hline High Health Instability & $1681(4.3 \%)$ & $369(4.6 \%)$ & $151(4.7 \%)$ & \\
\hline Very High Health Instability & 85 (0.2\%) & $20(0.2 \%)$ & 7 (0.2\%) & \\
\hline
\end{tabular}

Note: CHESS Changes in Health, End-Stage Disease, Signs, and Symptoms, COPD Chronic Obstructive Pulmonary Disease

* Functional status \& health characteristics were compared using analysis of variance (ANOVA) for continuous variables and chi-squared tests for categorical variables

Anglophones and Allophones were 17 and $41 \%$ more likely to experience harm in bilingual hospitals. After adjusting for potential confounders, which included both patient and hospital characteristics, there was no difference in the risk of harm when comparing patients from any linguistic group across hospitals stratified by language.

In Ontario, a total of 12 acute care hospitals are required by the French Language Services Act to provide all of their services in English and French [40]; we defined these hospitals as "bilingual hospitals" [40]. All hospitals may provide services in languages other than English (including French), but bilingual hospitals are the only hospitals that are required by law to do so. Francophones in these hospitals must be represented at all levels of management (e.g., human resources, senior management, and board of directors), and health care providers must actively offer services in French to their patients [48]. We hypothesized that Francophones would experience less harm in these hospitals, in part, because of improved patient-provider communication. As a result of the requirements imposed on bilingual hospitals, a larger proportion of health care providers in these hospitals are able to communicate in French (when compared to health care providers in other hospitals). Thus, fewer Francophone patients should face language barriers in bilingual hospitals. Previous studies have shown that patients who are treated in language-discordant environments are more likely to have poor health outcomes [26-29], although the impact of patient-provider language-discordance on the risk of harm has never been considered directly. Thus, it is possible that the lower risk of harm can be explained, to a certain extent, by the protective effects of being treated in a language-concordant environment. However, since the risk of harm did not persist after adjusting for confounding variables, 
Table 3 Characteristics of hospitals, by hospital language

\begin{tabular}{|c|c|c|c|}
\hline \multirow[t]{2}{*}{ Characteristic of Hospital } & \multicolumn{2}{|l|}{ Language of Hospital } & \multirow{2}{*}{$\begin{array}{l}P \\
\text { value }\end{array}$} \\
\hline & English-speaking $(N=147)$ & Bilingual $(N=12)$ & \\
\hline \multicolumn{4}{|l|}{ Academic Institution - no. (\%) } \\
\hline Yes & $19(12.9 \%)$ & $3(25.0 \%)$ & \multirow[t]{2}{*}{0.244} \\
\hline No & $128(87.1 \%)$ & $9(75.0 \%)$ & \\
\hline \multicolumn{4}{|l|}{ Emergency Department - no. (\%) } \\
\hline Yes & $140(95.2 \%)$ & $12(100 \%)$ & \multirow[t]{2}{*}{0.439} \\
\hline No & $7(4.8 \%)$ & $0(0 \%)$ & \\
\hline \multicolumn{4}{|l|}{ Urban/Rural Hospital - no. (\% } \\
\hline Urban & $74(50.3 \%)$ & $4(33.3 \%)$ & \multirow[t]{2}{*}{0.257} \\
\hline Rural & $73(49.7 \%)$ & $8(66.7 \%)$ & \\
\hline Total Number of Beds - mean +/- s.d. & $121.85 \pm 129.42$ & $47.44 \pm 48.57$ & 0.089 \\
\hline Number of ICU beds - mean $+/-$ s.d. & $11.20 \pm 15.76$ & $2.44 \pm 3.32$ & 0.100 \\
\hline Number of medical beds - mean $+/-$ s.d. & $51.65 \pm 65.69$ & $17.56 \pm 26.42$ & 0.124 \\
\hline Number of obstetric beds - mean $+/-$ s.d. & $9.78 \pm 13.47$ & $6.11 \pm 9.24$ & 0.424 \\
\hline Number of pediatric beds - mean $+/-$ s.d. & $4.21 \pm 7.24$ & $1.33 \pm 1.80$ & 0.238 \\
\hline Number of surgical beds - mean $+/-$ s.d. & $28.70 \pm 42.42$ & $9.67 \pm 16.29$ & 0.184 \\
\hline
\end{tabular}

Note: ICU Intensive Care Unit

* Characteristics were compared using t-tests for continuous variables and chi-squared tests for categorical variables

differences in the rates of harm cannot be attributed to linguistic factors alone.

We hypothesized that health care providers in bilingual hospitals would have a better understanding of the needs of linguistic minorities, given that Francophones are a minority linguistic group in Ontario. Thus, we believed that increased awareness and knowledge regarding the negative impacts of language barriers among health care providers in bilingual hospitals would translate to better outcomes for Allophones. However, Allophones were more likely to experience harm in bilingual hospitals than in English-speaking hospitals in the unadjusted analysis, and equally likely to experience harm in both bilingual and English-speaking hospitals in the adjusted analysis. According to the 2016 Canadian Census, $87.4 \%$ of Ontarians whose mother tongue is neither English nor French can conduct a conversation in English, while only $15.6 \%$ can conduct a conversation in French [2]. Thus, a larger proportion of Allophones can speak
English than French, which means that Allophones may experience more communication problems in bilingual hospitals. This could explain why Allophones did not experience more harm in English-speaking hospitals.

The risk of harm across bilingual and English-speaking hospitals did not persist in the adjusted analysis for any of the linguistic groups. It is possible that Anglophones and Allophones admitted to bilingual hospitals had a greater risk of experiencing harm (in the unadjusted analysis) because of systematic differences compared to patients of the same linguistic group admitted to English-speaking hospitals. Similarly, Francophones admitted to English-speaking hospitals may have had more risk factors for harm at baseline. Bilingual hospitals also had a higher rate of harm overall than English-speaking hospitals. This could be due to the fact that a greater proportion of bilingual hospitals are academic institutions, which generally have a higher rate of harm $[49,50]$. While this could provide an explanation for the

Table 4 Rate of harmful hospitalization, by patient linguistic group and hospital language*

\begin{tabular}{|c|c|c|c|c|}
\hline \multirow[t]{2}{*}{ Hospital Language } & \multicolumn{3}{|l|}{ Patient Linguistic Group } & \multirow[t]{2}{*}{$\boldsymbol{P}$ value } \\
\hline & Anglophone $(N=83,515)$ & Francophone $(N=16,873)$ & Allophone $(N=6491)$ & \\
\hline Overall Harmful Hospitalizations & $5255(6.29 \%)$ & $1038(6.15 \%)$ & $495(7.63 \%)$ & $<0.001$ \\
\hline \multicolumn{5}{|c|}{ Harmful Hospitalizations by Hospital Language } \\
\hline English-speaking ( $N=147)$ & $3318(5.96 \%)$ & $309(6.75 \%)$ & $243(6.50 \%)$ & 0.048 \\
\hline Bilingual $(N=12)$ & $1937(6.96 \%)$ & $729(5.93 \%)$ & $252(9.16 \%)$ & $<0.001$ \\
\hline$P$ valuet & $<0.001$ & 0.048 & $<0.001$ & \\
\hline
\end{tabular}

* Bold values denote significance at the 0.05 level

† Proportions of harmful hospitalizations were compared across patient linguistic groups and hospital language using chi-squared tests 


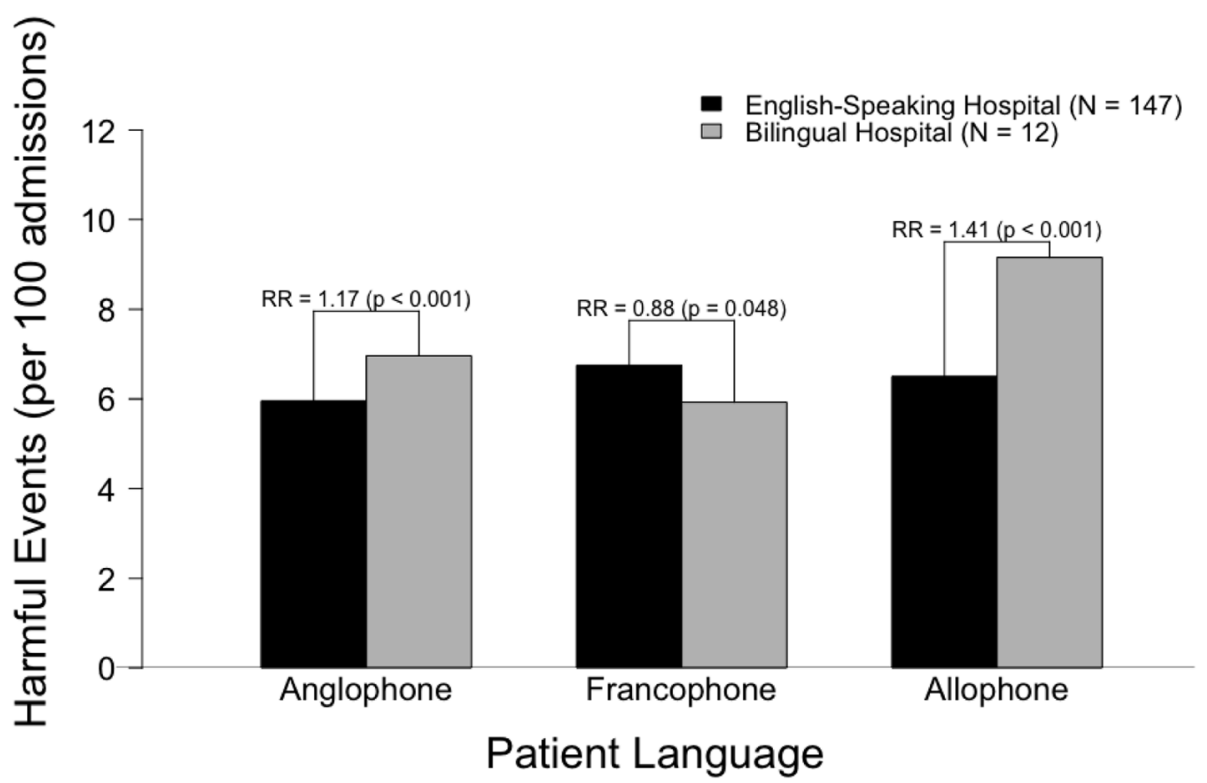

Fig. 1 Unadjusted relative risk of harm, stratified by hospital language

increased risk of harm for Anglophones and Allophones in bilingual hospitals, it does not explain the decreased risk observed for Francophones admitted to bilingual hospitals in the unadjusted analysis. Furthermore, while the adjusted relative risk of harm for Francophones in bilingual hospitals compared to English-speaking hospitals was not significant, the point estimate was further from 1 than the unadjusted estimate, suggesting a protective effect.

\section{Limitations}

We obtained primary language from RAI-HC home care assessments. During these assessments, interviewers determine the home care recipient's primary language by listening and observing and, if necessary, by asking the home care recipient to specify his or her primary language [31]. Many Ontarians speak multiple languages, and it is unclear how interviewers assigned primary language for such patients. Furthermore, the interviewers do not assess language proficiency, which is particularly important for multilingual patients. However, recent analyses performed by our group have shown that the language variable in the RAI-HC Database has a high level of agreement $(\mathrm{kappa}=0.76)$ with the language most often spoken at home, as determined by the Canadian Community Health Survey (Batista et al., unpublished data, 2019). Finally, since language is recorded prior to admission to hospital, misclassification of the exposure should be non-differential, leading the results to be biased towards the null.

Our interpretation of the results assumed that health care providers in bilingual and Englishspeaking hospitals had a higher level of proficiency in French and English, respectively, when compared to health care providers in hospitals with the opposite language status. Physicians who practice in Ontario can speak more than 130 different languages [51], and many physicians can speak multiple languages. Thus, many patients, especially Anglophones and Francophones, are likely to receive health care

Table 5 Relative risk of experiencing a harmful hospitalization, stratified by hospital language*

\begin{tabular}{|c|c|c|c|c|c|c|}
\hline & \multicolumn{2}{|c|}{ Model 1: Anglophones } & \multicolumn{2}{|c|}{ Model 2: Francophones } & \multicolumn{2}{|c|}{ Model 3: Allophones } \\
\hline & $\begin{array}{l}\text { English-speaking } \\
\text { Hospital }\end{array}$ & $\begin{array}{l}\text { Bilingual } \\
\text { Hospital }\end{array}$ & $\begin{array}{l}\text { English-speaking } \\
\text { Hospital }\end{array}$ & $\begin{array}{l}\text { Bilingual } \\
\text { Hospital }\end{array}$ & $\begin{array}{l}\text { English-speaking } \\
\text { Hospital }\end{array}$ & $\begin{array}{l}\text { Bilingual } \\
\text { Hospital }\end{array}$ \\
\hline $\begin{array}{l}\text { Unadjusted Relative Risk } \\
(95 \% \mathrm{Cl})\end{array}$ & 1.0 (ref) & $\begin{array}{l}1.17(1.11- \\
1.23)\end{array}$ & 1.0 (ref) & $\begin{array}{l}0.88(0.77- \\
0.99)\end{array}$ & 1.0 (ref) & $\begin{array}{l}1.41(1.19- \\
1.67)\end{array}$ \\
\hline $\begin{array}{l}\text { Adjusted Relative Risk (95\% } \\
\text { Cl)† }\end{array}$ & 1.0 (ref) & $\begin{array}{l}0.89(0.69- \\
1.15)\end{array}$ & 1.0 (ref) & $\begin{array}{l}0.75(0.49- \\
1.13)\end{array}$ & 1.0 (ref) & $\begin{array}{l}0.98(0.82- \\
1.17)\end{array}$ \\
\hline
\end{tabular}

* Bold values denote significance at the 0.05 level

† Adjusted for age at admission, sex, marital status, education, neighbourhood-level income quintile, urban/rural residence, Charlson Comorbidity Index, Activities of Daily Living (ADL) scale, Cognitive Performance Scale, academic institution (yes/no), emergency department at hospital (yes/no), urban/rural hospital, number of ICU beds, number of medical beds, number of obstetric beds, number of pediatric beds, number of surgical beds 


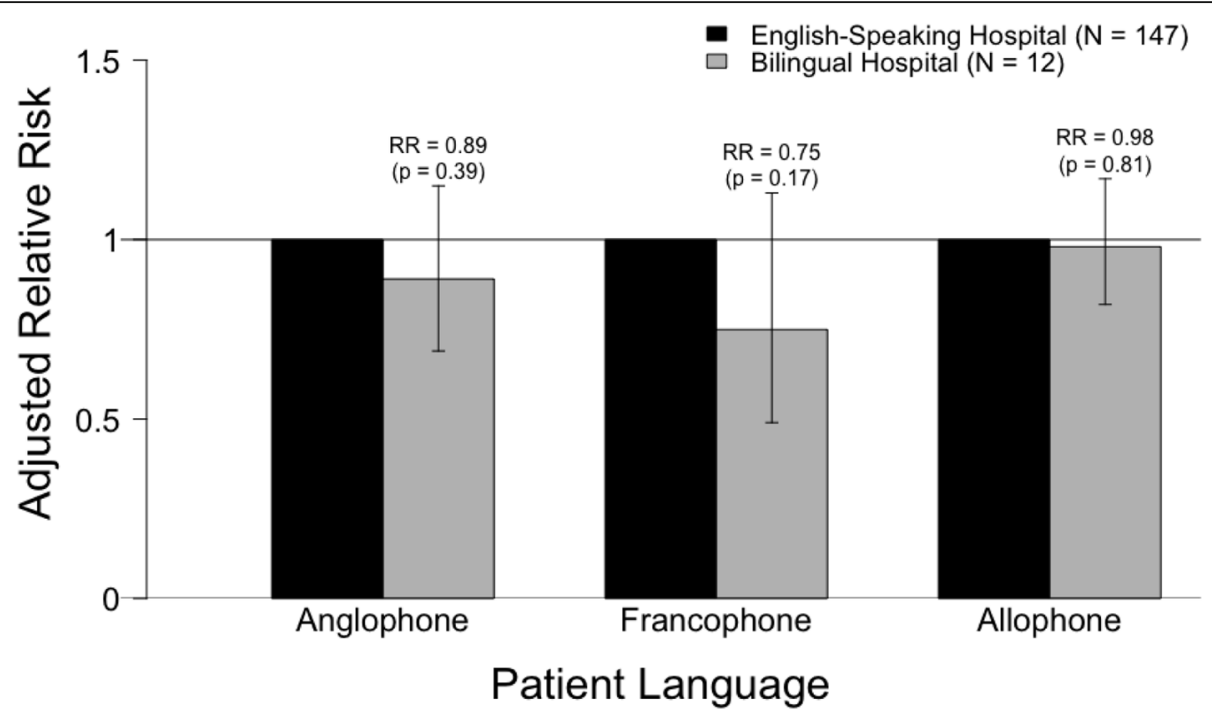

Fig. 2 Adjusted relative risk of harm, stratified by hospital language*. * Adjusted for age at admission, sex, marital status, education, neighbourhood-level income quintile, urban/rural residence, Charlson Comorbidity Index, Activities of Daily Living (ADL) scale, Cognitive Performance Scale, academic institution (yes/no), emergency department at hospital (yes/no), urban/rural hospital, number of ICU beds, number of medical beds, number of obstetric beds, number of pediatric beds, number of surgical beds

services in their primary language even in hospitals that are not required by law to do so. However, since the language employed during patient-provider encounters is not recorded, we do not know whether individual encounters occurred in the patient's primary language, and we cannot account for this in our analysis. Some hospitals are required by law to provide some (but not all) of their services in both French and English (partially bilingual hospitals) [40]. In this study, we compared rates of harm in hospitals required by law to provide all of their services in English and French to other hospitals, including partially bilingual hospitals. As a result, any effect attributed to patient-provider language barriers is likely underestimated, since some of the hospitals identified in this study as English-speaking (4 in Champlain LHIN and 6 in North-East LHIN) are in fact required by law to provide certain services in both French and English. Finally, our study was conducted in two geographic regions within a Canadian province with one official language (English) and one language for which the provision of services is guaranteed within certain hospitals (French). To our knowledge, no other jurisdiction in North America guarantees the provision of health care services to minority linguistic groups to the extent that the French Language Services Act guarantees access to services in French. Thus, our results may not be generalizable to other regions within Ontario or Canada or to populations with different legislation regarding language rights (e.g., Anglophone minority in Quebec and Francophone minority outside of Ontario).

\section{Conclusions}

In this study, Allophone home care recipients residing in Eastern and North-Eastern Ontario were more likely to experience a harmful hospitalization than Anglophones and Francophones. Furthermore, patients were less likely to experience harm in language-concordant hospitals (i.e., Anglophones and Allophones in English-speaking hospitals and Francophones in bilingual hospitals). However, the risk of harm due to language-discordance did not persist after adjusting for confounding variables. Thus, the differences in the rates of harm cannot be attributed to linguistic factors alone; the disparities are likely due, at least in part, to differences in patient and/ or hospital characteristics. Further research is needed to understand the mechanism that gives rise to these disparities.

\section{Supplementary information}

Supplementary information accompanies this paper at https://doi.org/10. 1186/s12913-020-05213-6.

Additional file 1. Chronic conditions. Description of chronic conditions identified using algorithms validated by ICES.

Additional file 2. Categories and subcategories of harmful events. Description of in-hospital harmful events identified using the Hospital Harm Indicator.

\section{Abbreviations}

ADL: Activities of Daily Living; ANOVA: Analysis of Variance; CHESS: Changes in Health, End-Stage Disease, Signs and Symptoms; DAD: Discharge Abstract Database; ICES : Institute for Clinical Evaluative Sciences; OHIP: Ontario Health Insurance Plan; RAI-HC: Resident Assessment Instrument for Home Care 


\section{Acknowledgements}

We wish to acknowledge the Canadian Institute for Health Information for providing us with the code for the Hospital Harm Indicator.

\section{Authors' contributions}

The manuscript is co-authored by MR, RB, RT, EG, ER, SC, DP, PT. MR and DP conceived the original idea. MR and SC performed a literature review to obtain relevant background information necessary to design the study. $M R, R B$, EG, and PT designed the study and interpreted the results. RT performed the statistical analyses. MR drafted the manuscript in consultation with ER, and all authors provided critical feedback and suggestions to prepare the final manuscript. MR had full access to all the data in the study and had final responsibility for the decision on content and publication submission. All of the authors gave final approval of the version to be published and agreed to be accountable for all aspects of the work. None of the authors have a competing interest.

\section{Funding}

This study was primarily supported by Institut du Savoir Montfort and by the MOHLTC Health System Research Fund Program Award for the QUality for Individuals who require Long-Term support (QUILT) Network (grant no. 255). This study was also supported by ICES, which is funded by an annual grant from the Ontario MOHLTC. ICES has been approved by Ontario's Information and Privacy Commissioner since 2005. The opinions, results, and conclusions reported in this article are those of the authors and are independent from the funding sources. No endorsement by ICES or the Ontario MOHLTC is intended or should be inferred. ICES collects information most notably for purposes of section 45 of Ontario's Personal Health Information Protection Act (PHIPA).

\section{Availability of data and materials}

The data that support the findings of this study are available from ICES but restrictions apply to the availability of these data, which were used under license for the current study, and so are not publicly available. Data are however available from the authors upon reasonable request and with permission of ICES.

\section{Ethics approval and consent to participate}

The use of data in this project was authorized under section 45 of Ontario's Personal Health Information Protection Act, which does not require review by a Research Ethics Board.

\section{Consent for publication}

Not applicable.

\section{Competing interests}

None of the authors have a competing interest.

\section{Author details}

${ }^{1}$ Faculty of Medicine, University of Ottawa, 451 Smyth Rd, Ottawa, ON K1H 8L1, Canada. ${ }^{2}$ Institut du Savoir Montfort, Ottawa, Canada. ${ }^{3}$ Department of Medicine, Ottawa Hospital Research Institute, Ottawa, Canada. ${ }^{4}$ ICES, Ottawa, Canada. ${ }^{5}$ Faculty of Health Sciences, University of Ottawa, Ottawa, Canada. ${ }^{6}$ Bruyère Research Institute, Ottawa, Canada.

Received: 20 December 2019 Accepted: 13 April 2020 Published online: 21 April 2020

\section{References}

1. U.S. Census Bureau. 2017 American community survey 1-year estimates. 2018. https://factfinder.census.gov/faces/tableservices/jsf/pages/ productview.xhtml?pid=ACS_07_1YR_B16001\&prodType=table. Accessed 2 Sep 2019.

2. Statistics Canada. Data tables, 2016 Census. 2019. https://www12.statcan.gc. ca/census-recensement/2016/dp-pd/dt-td/Lp-eng.cfm?\%20LANG= $E \& A P A T H=3 \& D E T A I L=0 \& D I M=0 \& F L=A \& F R E E=0 \& G C=0 \& G I D=0 \& G K=0 \& G R P=$ 1\&PID $=0 \& P R I D=10 \& P T Y P E=109445 \& S=0 \& S H O W A L L=0 \& S U B=888 \& T e m p o r a l=$ 2016,2017\&THEME $=118 \& V I D=0 \& V N A M E E=\& V N A M E F=$. Accessed 1 Dec 2019.

3. American College of Physicians. Racial and Ethnic Disparities in Health Care, Updated 2010. 2010. https://www.acponline.org/acp_policy/policies/racial_ ethnic_disparities_2010.pdf. Accessed 1 Dec 2019.
4. Flores G. Committee on pediatric research. Technical report — racial and ethnic disparities in the health and health Care of Children. Pediatrics. 2010; 125:e979-1020.

5. Lau M, Lin H, Flores G. Racial/ethnic disparities in health and health care among U.S. adolescents. Health Serv Res. 2012;47:2031-59.

6. Bouchard L, Desmeules M. Les minorités linguistiques du Canada et la santé. Healthcare Policy. 2013;9(Special Issue):38-47.

7. Bowen S. Language barriers in access to health care. Health Canada 2001. https://www.canada.ca/content/dam/hc-sc/migration/hc-sc/hcs-sss/alt_ formats/hpb-dgps/pdf/pubs/2001-lang-acces/2001-lang-acces-eng.pdf. Accessed 1 Jun 2019.

8. Yeo S. Language barriers and access to care. Annu Rev Nurs Res. 2004;22: 59-73.

9. Goldman RD, Amin P, Macpherson A. Language and length of stay in the pediatric emergency department. Pediatr Emerg Care. 2006;22:640-3.

10. John-Baptiste A, Naglie G, Tomlinson G, Alibhai SMH, Etchells E, Cheung A, et al. The effect of English language proficiency on length of stay and inhospital mortality. J Gen Intern Med. 2004;19:221-8.

11. Sarver J, Baker DW. Effect of language barriers on follow-up appointments after an emergency department visit. J Gen Intern Med. 2000;15:256-64.

12. Karliner LS, Auerbach A, Nápoles A, Schillinger D, Nickleach D, Pérez-Stable EJ. Language barriers and understanding of hospital discharge instructions. Med Care. 2012;50:283-9.

13. Karliner $L S$, Kim SE, Meltzer DO, Auerbach AD. Influence of language barriers on outcomes of hospital care for general medicine inpatients. J Hosp Med. 2010;5:276-82.

14. Gallagher RA, Porter S, Monuteaux MC, Stack AM. Unscheduled return visits to the emergency department: the impact of language. Pediatr Emerg Care. 2013:29:579-83.

15. Cohen AL, Rivara F, Marcuse EK, McPhillips H, Davis R. Are language barriers associated with serious medical events in hospitalized pediatric patients? Pediatrics. 2005;116:575-9.

16. Lion KC, Rafton SA, Shafii J, Brownstein D, Michel E, Tolman M, et al. Association between language, serious adverse events, and length of stay among hospitalized children. Hosp Pediatr. 2013;3:219-25.

17. Hines AL, Andrews RM, Moy E, Barrett ML, Coffey RM. Disparities in rates of inpatient mortality and adverse events: race/ethnicity and language as independent contributors. Int J Environ Res Public Health. 2014;11:13017-34.

18. Sentell T, Chang A, Ahn HJ, Miyamura J. Maternal language and adverse birth outcomes in a statewide analysis. Women Health. 2016;56:257-80.

19. Manson A. Languange concordance as a determinant of patient compliance and emergency room use in patients with asthma. Med Care. 1988;26:1119-28.

20. Seijo R, Gomez H, Freidenberg J. Language as a communication barrier in medical Care for Hispanic Patients. Hisp J Behav Sci. 1991;13:363-76.

21. Rivadeneyra R, Elderkin-thompson V, Silver RC, Waitzkin H. Patient centeredness in medical encounters requiring an interpreter. Am J Med. 2000;108:470-4.

22. Pérez-Stable EJ, Nápoles-Springer A, Miramontes JM. The effects of ethnicity and language on medical outcomes of patients with hypertension or diabetes communication the effects of ethnicity and language on medical outcomes of patients with hypertension or diabetes. Med Care. 1997;35: 1212-9.

23. Shapiro J, Saltzer EB. Cross-cultural aspects of physician-patient communications patterns. Urban Health. 1981;10:10-5.

24. Ngo-Metzger Q, Sorkin DH, Phillips RS, Greenfield S, Massagli MP, Clarridge $B$, et al. Providing high-quality Care for Limited English Proficient Patients: the importance of language concordance and interpreter use. J Gen Intern Med. 2007;22(Suppl 2):324-30.

25. Eamranond PP, Davis RB, Wee RSP, Wee CC. Patient-physician language concordance and lifestyle counseling among Spanish-speaking patients. J Immigr Minor Health. 2009;11:494-8.

26. Mehler P, Lundgren R, Pines I, Doll K. A community study of language concordance in Russian patients with diabetes. Ethn Dis. 2004;14:584-8.

27. Palau-Collazo M, Rose P, Sikes K, Kim G, Benavides V, Urban A, et al. Effectiveness of a Spanish language Clinic for Hispanic Youth with type 1 diabetes. Endocr Pract. 2013;19:800-4.

28. Parker MM, Fernández A, Moffet HH, Grant RW, Torreblanca A, Karter AJ. Association of Patient-Physician Language Concordance and Glycemic Control for limited-English proficiency Latinos with type 2 diabetes. JAMA Intern Med. 2017;177:380-7. 
29. Gardam M, Verma G, Campbell A, Wang J, Khan K. Impact of the patientprovider relationship on the survival of foreign born outpatients with tuberculosis. J Immigr Minor Health. 2009;11:437-45.

30. Canadian Institute for Health Information. Measuring Patient Harm in Canadian Hospitals. 2016. https://secure.cihi.ca/free_products/cihi_cpsi_ hospital_harm_en.pdf. Accessed 1 Jun 2018.

31. Morris J, Fries B, Bernabei R, et al. RAl-Home Care (RAI-HC) User's manual, Canadian version, September 2010. Canadian Institute for Health Information 2010. https://secure.cihi.ca/estore/productFamily.htm?pf= PFC1554\&lang=en\&media $=0$. Accessed 1 Jun 2018.

32. Canadian Patient Safety Institute. Safety at home: a pan-Canadian home care safety study. 2013. https://www.patientsafetyinstitute.ca/en/ toolsResources/Research/commissionedResearch/SafetyatHome/Documents/ Safety\%20At\%20Home\%20Care.pdf. Accessed 1 Jun 2018.

33. Mondor L, Maxwell CJ, Bronskill SE, Gruneir A, Wodchis WP. The relative impact of chronic conditions and multimorbidity on health-related quality of life in Ontario long-stay home care clients. Qual Life Res. 2016;25:2619-32.

34. Barker P. Local health integration networks: the arrival of regional health authorities in Ontario. Presented at Annual Meeting of the Canadian Political Science Association. Saskatoon, SK; 2007.

35. Hsu AT, Manuel DG, Taljaard M, Chalifoux M, Bennett C, Costa AP, et al. Algorithm for predicting death among older adults in the home care setting: study protocol for the risk evaluation for support: predictions for elder-life in the community tool (RESPECT). BMJ Open. 2016:6:013666

36. Stephenson A, Hux J, Tullis E, Austin PC, Corey M, Ray J. Socioeconomic status and risk of hospitalization among individuals with cystic fibrosis in Ontario. Canada Pediatr Pulmonol. 2011;46:376-84.

37. Koné Pefoyo AJ, Bronskill SE, Gruneir A, Calzavara A, Thavorn K, Petrosyan Y, et al. The increasing burden and complexity of multimorbidity. BMC Public Health. 2015;15.

38. Gruneir A, Bronskill SE, Maxwell CJ, Bai YQ, Kone AJ, Thavorn K, et al. The association between multimorbidity and hospitalization is modified by individual demographics and physician continuity of care : a retrospective cohort study. BMC Health Serv Res. 2016;16.

39. Muggah E, Graves E, Bennett C, Manuel DG. The impact of multiple chronic diseases on ambulatory care use; a population based study in Ontario. Canada BMC Health Serv Res. 2012;12.

40. Government of Ontario. O. Reg. 398/93: Designation of Public Services Agencies. https://wnw.ontario.ca/laws/regulation/930398. Accessed 6 Oct 2019.

41. Katz D, Baptista J, Azen S, Pike M. Obtaining confidence intervals for the risk ratio in cohort studies. Biometrics. 2019;34:469-74.

42. Zou G. A modified Poisson regression approach to prospective studies with binary data. Am J Epidemiol. 2004;159:702-6.

43. Zou GY, Donner A. Extension of the modified Poisson regression model to prospective studies with correlated binary data. Stat Methods Med Res. 2011;22:661-70.

44. Yelland LN, Salter AB, Ryan P. Performance of the modified poisson regression approach for estimating relative risks from clustered prospective data. Am J Epidemiol. 2011;174:984-92.

45. Charlson M, Pompei P, Ales K, MacKenzie C. A new method of classifying prognostic comorbidity in longitudinal studies: development and validation. J Chronic Dis. 1987:40:373-83.

46. Morris JN, Pries B, Morris S. Scaling ADLs within the MDS. J Gerontol. 1999; 54:546-53.

47. Morris JN, Fries BE, Mehr DR, Hawes C, Phillips C, Mor V, et al. MDS cognitive performance scale. J Gerontol. 1994;49:174-82.

48. Office of the French Language Services Commissionner of Ontario. Study on Designation: Revitalizing the Provision of French Language Services. https://csfontario.ca/en/articles/6284. Accessed 1 Dec 2019.

49. Brennan TA, Hebert LE, Laird NM, Lawthers A, Thorpe KE, Leape LL, et al. Hospital characteristics associated with adverse events and substandard care. JAMA. 1991;265:3265-9.

50. Sousa P, Uva AS, Serranheira F, Uva MS, Nunes C. Patient and hospital characteristics that influence incidence of adverse events in acute public hospitals in Portugal: a retrospective cohort study. Int I Qual Heal Care. 2018;30:132-7.

51. College of Physicians and Surgeons of Ontario. Doctor Search. 2019. https:// doctors.cpso.on.ca/?search=general. Accessed 30 Oct 2019.

\section{Publisher's Note}

Springer Nature remains neutral with regard to jurisdictional claims in published maps and institutional affiliations.

Ready to submit your research? Choose BMC and benefit from:

- fast, convenient online submission

- thorough peer review by experienced researchers in your field

- rapid publication on acceptance

- support for research data, including large and complex data types

- gold Open Access which fosters wider collaboration and increased citations

- maximum visibility for your research: over $100 \mathrm{M}$ website views per year

At $\mathrm{BMC}$, research is always in progress.

Learn more biomedcentral.com/submissions 